\title{
Attitude Survey of Medical School Staff After Simulated Patient Experiences
}

\author{
Tokyo Medical University

\section{Yuki KUBOTA} \\ Tokyo Medical University

\section{Yoji HIRAYAMA} \\ Tokyo Medical University \\ Junji OTAKI \\ Tokyo Medical University \\ Hiroshi MITOMA \\ Tokyo Medical University
}

Yoshimi Harada ( $\nabla$ yharada@tokyo-med.ac.jp)

\section{Research Article}

Keywords: Simulated patient, OSCE, staff, staff development

Posted Date: February 11th, 2021

DOI: https://doi.org/10.21203/rs.3.rs-181613/v1

License: (c) (i) This work is licensed under a Creative Commons Attribution 4.0 International License. Read Full License 
Research article

Attitude Survey of Medical School Staff after Simulated Patient Experiences

Yoshimi HARADA ${ }^{1,2,3}$, Yuki KUBOTA ${ }^{2}$, Yoji HIRAYAMA ${ }^{2,3}$, Junji OTAKI ${ }^{1,3}$, Hiroshi MITOMA ${ }^{1,2}$

1) Tokyo Medical University, Department of Medical Education; 2) Tokyo Medical University, Department of Medical Education Promotion Center; 3) Tokyo Medical University, Department of General Medicine and Primary Care

\section{Abstract}

Background:

With the spread of medical communication education and objective structured clinical examination (OSCE), greater numbers of simulated patients/standardized patients (SPs) will likely be needed throughout Japan. At Tokyo Medical University, non-medical professional medical school staff have acted as SPs in post-clinical clerkship OSCE. There are no reports of any staff other than teaching staff and medical staff acting as SPs. The significance of large numbers of medical school staff acting as SPs needs to be clarified.

Methods:

We conducted a questionnaire survey of staff after acting as SPs. The questionnaire was developed from semi-structured interviews.

Results:

The majority of responses were positive, saying that they had learned about the 
testing and students and that they felt the importance of communication for doctors. Many respondents said that staff of a medical school should experience being an SP and that many staff should try it.

\section{Conclusions:}

For medical school staff, being an SP is one way to learn about student education. Japan has problems with SPs becoming older and fewer in number nationwide, but SP numbers may be supplemented by staff.

Keywords:

Simulated patient, OSCE, staff, staff development

\section{Background}

Medical doctors are professional who need to be strongly specialized. As the medical techniques and medical knowledge that doctors require expand at increasing pace, education in the professionalism they need as specialists is important. One of the pillars of professionalism is communication techniques ${ }^{1}$. The standard form of medical communication is the medical interview with a patient. Role-playing-meaning practice with simulated patients/standardized patients (SP) — is useful in training and testing for medical interviews ${ }^{2,3,4}$. Most medical schools now conduct medical interview practice with SPs.

Objective structured clinical examination (OSCE) is widely used for evaluating the acquisition of prowess at medical interviews and other clinical skills that are difficult to 
assess with paper tests, such as judgment, technique and manner. In Japan, before students without medical qualifications start clinical clerkships, common achievement testing OSCE is conducted to verify that the students are well equipped with basic knowledge, skills and manner, including good communication ability. "Common achievement testing prior to clinical clerkship" has been conducted officially since 2006; medical students throughout Japan have taken the tests ${ }^{5}$. After clinical clerkship too, a number of schools have been conducting post-clinical clerkship OSCE to evaluate whether the abilities required for starting clinical practice, in terms of skills and manner, have been acquired. Since 2020, common achievement testing has been conducted for post-clinical clerkship OSCE ${ }^{6}$.

With the spread of medical communication education and OSCE, greater numbers of SPs will probably be needed throughout Japan. Although a number of medical school have started to develop $\mathrm{SPs}^{7}$ as well as using external SP group, a shortage of SPs is expected in the future. Since FY2017, in addition to using external SP associations, Tokyo Medical University has been training medical school staff as SPs and they have participated in OSCE. In FY2017, Tokyo Medical University, principally the Department of Medical Education Promotion Center, founded the "Tokyo Medical University Simulated Patient Association", mainly with retirees from the university, and started training them as SPs. A ministerial ordinance partially revising university and college establishment criteria ${ }^{8}$ has called for the provision of training (staff development (SD)) opportunities so that staff can learn the knowledge and skills required for managing a university and can improve their abilities and attributes. For staff of a medical school from a wide range of fields, acting as SPs is likely to be useful as SD for learning about student education. There are no reports reviewing how SPs are recruited 
around the world. There is a report that people involved with medical departments and medical schools are active as SPs in $37 \%$ of those institutions in Japan, accounting for $8 \%$ of their $\mathrm{SPs}^{7}$. There are no reports on whether staff other than teaching staff and medical staff are active among those SPs. The significance of large numbers of medical school staff acting as SPs needs to be clarified. At Tokyo Medical University, staff have acted as SPs in post-clinical clerkship OSCE since FY2017. We sought to clarify how acting as SPs has affected the awareness of medical school staff, what needs to be considered when developing SPs in future, and whether SP activity is useful as part of SD.

Methods

Subjects

1. Interview survey

The post-clinical clerkship OSCE in FY2017 was held on July 26. SPs from both an external association and medical school staff acted as SPs. All the staff acting as SPs were subjects of the interview survey.

\section{Questionnaire survey}

The post-clinical clerkship OSCE in FY2018 was held on July 20 and 21, and in FY2019 on July 19 and 20. In FY2020, because of the COVID-19 pandemic, the postclinical clerkship OSCE was scaled down and held on September 19. Each year, as well 
as SPs from an external association, medical school staff and members of the Tokyo Medical University Simulated Patient Association, who are mainly retired university staff, acted as SPs. All the university staff and members of the Tokyo Medical University Simulated Patient Association who acted as SPs were subjects of the questionnaire survey.

\section{Processes}

1. Development of the questionnaire

\section{1-1. Semi-structured interviews}

We prepared an interview guide for the research subjects and conducted semistructured interviews from November 29 to December 13, 2017. The interview guide was prepared by discussion among the research collaborators. We asked the subjects if they had known about OSCE and SPs, if they had known what kind of teaching and testing the medical students received, if they had learned anything from being an SP, and how they felt about their SP experience.

\section{1-2. Analysis and questionnaire development}

Voice data recorded in the interviews was transcribed and was coded and categorized by a number of researchers and research collaborators. The questionnaire was developed using a Likert scale for each category with responses in five levels, from 1 to 5.

\section{Questionnaire survey}

2-1. The questionnaire survey

After the end of post-clinical clerkship OSCE in FY2018, FY2019 and FY2020, we distributed the questionnaires we had prepared. We asked for the responses to be 
returned through the school's internal mail within three weeks.

\section{2-2. Analysis}

We judged the reliability of the questionnaire survey with Cronbach's alpha coefficient. We tested annual trends in the responses about knowledge of OSCE and knowledge of SPs with chi-squared tests. The statistical software used was IBM SPSS Statistics $27^{\mathrm{R}}$ and the threshold for significance was $\mathrm{P}<0.05$.

Results

\section{Semi-structured interviews}

Of a total of 12 staff who acted as SPs, ten took part in the interviews. We identified terms of interest in the transcribed data and used contextually appropriate words to express those ideas. We divided the responses into "positive opinions", "negative opinions" and "neutral opinions". Regarding the reasons for staff to become SPs, $60 \%$ said they were instructed by superiors and $40 \%$ said that they were in the age and sex groups being recruited. Regarding their feelings about their SP experience, there were many positive responses, including "I have learned about the situations of testing and students", "it was stressful at first but I gradually got used to it", "I felt involved in the frontline of education", "we should continue to observe technique and manner rather than just focusing on knowledge" and "it was fun". There were also some negative responses, including "it was difficult to remember the scenario", "I felt stressed because it affects their graduation chances" and "it has no relation to my work". When asked whether they would recommend participation to other staff, there were many positive 
comments. Comments for people participating in SP development in the future were all positive, including "many staff should experience it" and "I felt actively involved in education". About techniques for practicing to be an SP, the responses included "I made a small copy of the scenario ", "I looked up specialist terms on the Internet" and "I practiced with my family".

2. The questionnaire survey

We received responses from 56 of the staff who acted as SPs: 15 of a total of 20 in FY2018, 22 of 29 in FY2019 and 19 of 20 in FY2020. The proportion acting as SPs for at least a second year was zero in FY2018, 34\% in FY2019 and 21\% in FY2020 (Fig. 1). The proportion who have worked in a post involved with education was substantially constant at $86-89 \%$. The proportion who said their reason for becoming an SP was because they wanted to was 40\% in FY2018, 15\% in FY2019 and 47\% in FY2020. The proportion with specific knowledge of OSCE was $13 \%$ in FY2018, rising sharply to $82 \%$ in FY2019 and falling to 47\% in FY2020. The proportions with specific knowledge of SPs were $13 \%, 73 \%$ and $37 \%$ in the three years. Regarding how the staff felt about their SP experience (Fig. 2), "agree somewhat" and "strongly agree" responses aggregated over the three years were 94\% for "I have learned about conditions of testing and students", 57\% for "it was difficult to remember the scenario", $68 \%$ for "it was fun", $84 \%$ for "I felt involved in the frontline of education" and $98 \%$ for "I felt the importance of communication". Regarding staff acting as SPs in graduation OSCE, 69\% agreed with "if I have the opportunity, I want to do it again", 50\% with "it has no relation to my current work", $41 \%$ with "other staff are busy and need to be actively encouraged to do it", $80 \%$ with "staff of a medical school should do it" (Fig. 3), 
$87 \%$ with "many staff should experience it", 59\% with "simulated patient training sessions should be started" and 35\% with "there should be a system for certifying staff who take simulated patient training" (Fig. 4).

The Cronbach alpha coefficient was 0.717 .

\section{Discussion}

In the first year, we conducted semi-structured interviews about the awareness staff gained from being SPs. Many staff had had no specific knowledge of OSCE or SPs but many had positive feelings about acting as SPs. Their motives for participation were passive reasons such as management instructions, but they had positive feelings after participating. Even when acting as an SP in OSCE had no direct relation to their own work, they gave opinions indicating that participation in student education contributed to their motivation as medical university staff

We developed the questionnaire on the basis of these results and conducted the questionnaire survey from the next year. In FY2018, few of the respondents knew specific details about OSCE or SPs, but awareness was higher in FY2019. The proportion with awareness of OSCE or SPs rose even accounting for those with professional experience relating to education and those who had SP experience before FY2019, which suggests that knowledge of OSCE and other details of medical education was spreading among the wider staff. In FY2020, the proportion with some awareness had fallen somewhat. This may be related to the COVID-19 pandemic: 
because external associations could not help with the pre-clinical clerkship OSCE, staff were asked to fill all the SP positions; so, a large number of staff took part in the preand post-clinical clerkship tests. The proportion of staff who were self-motivated to act as SPs did not show a consistent trend over the years; it is unrelated to levels of awareness of OSCE and SPs. Although we do not have specific details, we can say that greater numbers of staff are coming forward.

There were big differences between the three survey years in respondents' feelings about being an SP. Many responded that they felt involved in the frontline of education and that they felt the importance of communication; more than half responded that it was fun. Some responded that it was difficult to remember the scenario. Many responded that, although it has no relation to their current work and that while they had mixed feelings about recommending participation to other staff members, it was necessary for medical university staff to participate; if they had the opportunity, they wanted to participate again. A lot felt that many staff should experience being an SP, but few were positive about a system for accrediting participating staff. Being an SP may be useful for staff, as one way to learn about student education for SD.

In a questionnaire survey of internal examiners participating in OSCE (the results are not detailed here), many approved of the quality of the SPs, saying that they were good; they were compared favorably with SPs from external associations. Feedback from external examiners indicated that they rated the SPs highly and think the SPs can assure the quality of OSCE.

The legal status of "Student Doctors" in Japan is an important matter; reports have suggested that common achievement testing in pre-clinical clerkship OSCE should be formalized ${ }^{9}$. Formalizing this common achievement testing will require further 
improvements in consistency, the establishment of systems for nationwide initiatives and consideration of establishing a training system for $\mathrm{SPs}^{9}$. However, increasing ages and serious shortage of SPs have been identified as impediments to this ${ }^{10}$. Medical school staff fall into a wide range of age bands, from twenties to sixties; having staff participate as SPs is one way to address the problem. Opinions from examiners indicate that steady levels are currently being maintained. However, standardized SP training and a system for approving SP trainers should be considered ${ }^{11}$. How staff will become accredited as SPs is a question for the future.

A limitation of this research is that it examined only a single institution. Therefore, there were limits on the numbers of respondents and the diversity of their backgrounds; this research may be inadequate as a basis for generalization. The scenarios used in OSCE are not uniform but numerous; so, effects of the scenarios cannot be disregarded.

Conclusions

Medical school staff have been acting as SPs in post-clinical clerkship OSCE. Many of them had positive opinions about acting as SPs, which is one way to learn about medical education. Nationwide problems with aging and a shortage of SPs have been identified. Numbers may be supplemented by school staff becoming SPs. 
Declarations

Ethics approval and consent to participate

The study was performed in accordance with the Declaration of Helsinki. Informed consent was obtained from all subjects (all participants are above 18). The interview survey was recognized by the Medical Research Ethics Review of Tokyo Medical University as research outside the scope of the "Ethics guidelines for medical research on humans"; written consent was obtained from the research subjects. The questionnaire survey was approved by the Medical Research Ethics Review of Tokyo Medical University (reference number T2018-0003). Participants were informed about the purpose of the study, and they were assured that their responses would only be used anonymously for research purposes on a voluntary basis. Consent for participation in the research was returned with the responses to the questionnaire.

Consent for publication

Not applicable.

Availability of data and material

All data generated and analyzed during the current study are included in this published article.

Competing interests

The authors declare that they have no competing interests. 
Funding

No internal or external sources of funding were used to support this work.

Authors' contributions

All authors made substantial contributions to conception and design and finally approved the manuscript. YHa, YK and research collaborators participated in data collection and interpreted the data. $\mathrm{YHi}, \mathrm{HM}$ and $\mathrm{JO}$ participated in data interpretation and revised the manuscript critically for important intellectual content.

Acknowledgements

We are grateful to all the staff who acted as SPs in OSCE and cooperated with the survey. We also thank all staff of the Department of Medical Education Promotion Center, Tokyo Medical University who collaborated with the research.

Abbreviations

OSCE: objective structured clinical examination

SP: simulated patient / standardized patient

SD: staff development

\section{References}


1) Arnold L, Stern DT : What is Medical Professionalism? In Sten DT (ed):

Measuring Medical Professionalism. Oxford university press New York, pp.15-37, 2006

2) Rees C, Sheard C, McPherson A. Communication skills assessment: the perceptions of medical students at the University of Nottingham. Med Educ 2002; 36: 868-78.

3) Chan CS, Wun YT, Cheung A, Dickinson JA, Chan KW, Lee HC, Yung YM. Communication skill of general practitioners: any room for improvement? How much can it be improved? Med Educ 2003; 37:514-26.

4) Yedidia MJ, Gillespie CC, Kachur E, Schwartz MD, Ockene J, Chepaitis AE, Snyder CW, Lazare A, Lipkin Jr M. Effect of communications training on medical student performance. JAMA 2003; 290: 1157-65.

5) Kozu T. Medical Education in Japan. Academic Medicine 2006; 81:1069-1075.

6) Komasawa N, Terasaki F, Nakano T, Kawata R. Relationships between objective structured clinical examination, computer-based testing, and clinical clerkship performance in Japanese medical students. PLoS ONE 2020; 15(3): e0230792.

7) Shimura T, Yoshii F, Yoshimura A, Abe K, Takahashi Y, Saeki H, Fujisaki K, Aso R, Inoue C. A Survey on Training of Simulated and Standardized Patients (SP) and SP Program in Undergraduate Medical Education in Japan 16th Committee of Educational Materials' Development of Japan Society for Medical Education. Medical Education (Japan) 2011; 42: 29-35.

8) Ministry of Education, Culture, Sports, Science and Technology. Ministerial Ordinance No. 18: Ordinance partially revising university and college establishment criteria in accordance with the provisions of Article 3 of the School Education Law (1947, act no. 26) [in Japanese]. URL: 
http://www.mext.go.jp/b_menu/hakusho/nc/_icsFiles/afieldfile/2016/04/26/1369942_1 .pdf (accessed 22 November 2020).

9) Ministry of Health, Labour and Welfare. Report from the Doctor Subcommittee of the Medical Ethics Council: Formalizing common achievement testing for seamless doctor training and the legal status of the "Student Doctor", May 2020 [in Japanese]. URL: https://www.mhlw.go.jp/content/10803000/000629953.pdf (accessed 11 December 2020).

10) Ministry of Health, Labour and Welfare. Doctor Subcommittee of the Medical Ethics Council (27 September 2019): Reference materials 2, The current state and issues of standardized and simulated patients, YAMAGUCHI Ikuko [in Japanese]. URL: https://www.mhlw.go.jp/content/10803000/000552398.pdf (accessed 22 November 2020).

11) Ministry of Health, Labour and Welfare. Doctor Subcommittee of the Medical Ethics Council (27 September 2019), meeting minutes [in Japanese]. URL: https://www.mhlw.go.jp/content/000555602.pdf (accessed 22 November 2020). 


\section{Figures}

How many times have you acted as a simulated patient in OSCE?
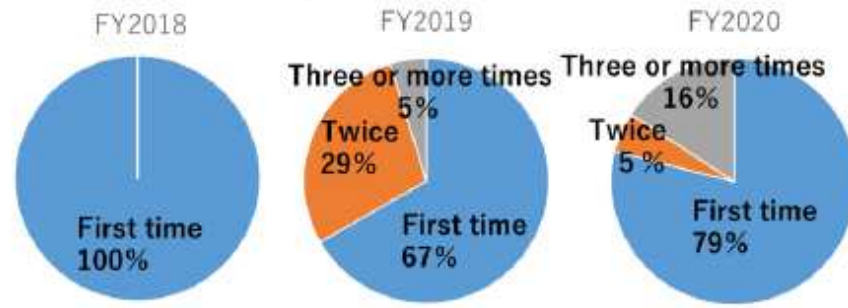

What prompted you to become a simulated patient?

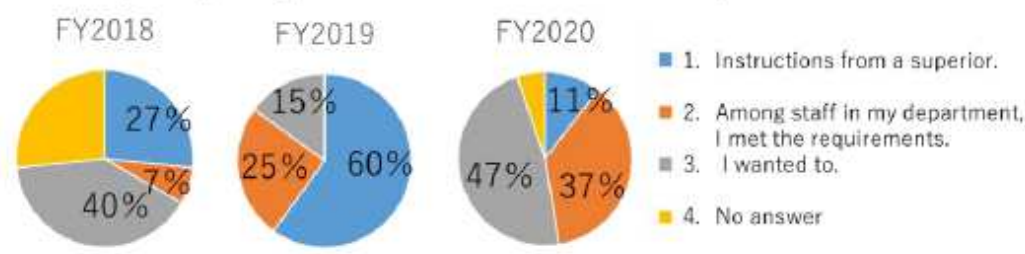

Have you ever worked in a post involved with education?
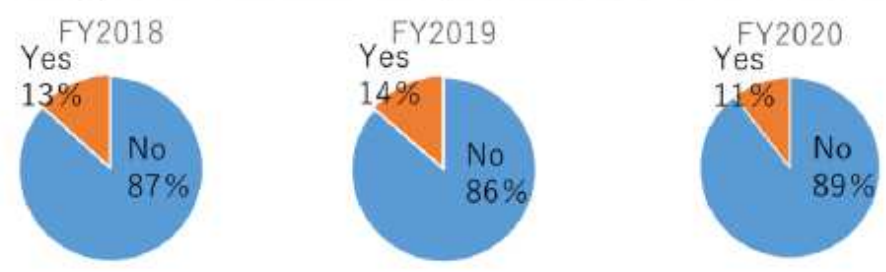

Did you know about OSCE?

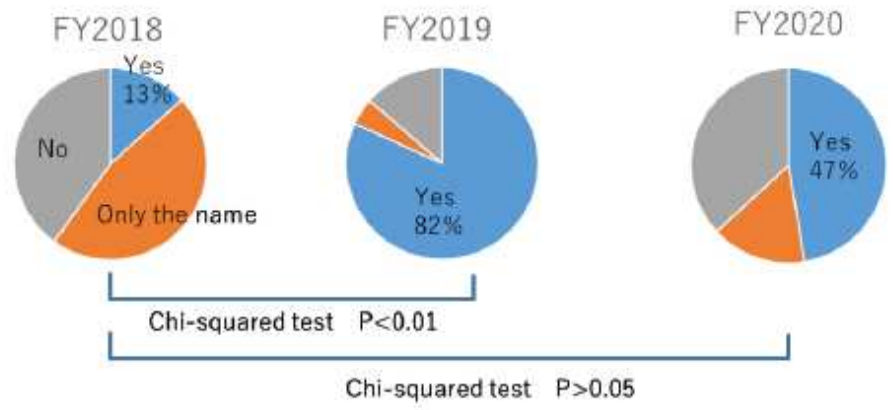

Did you know about simulated patients?

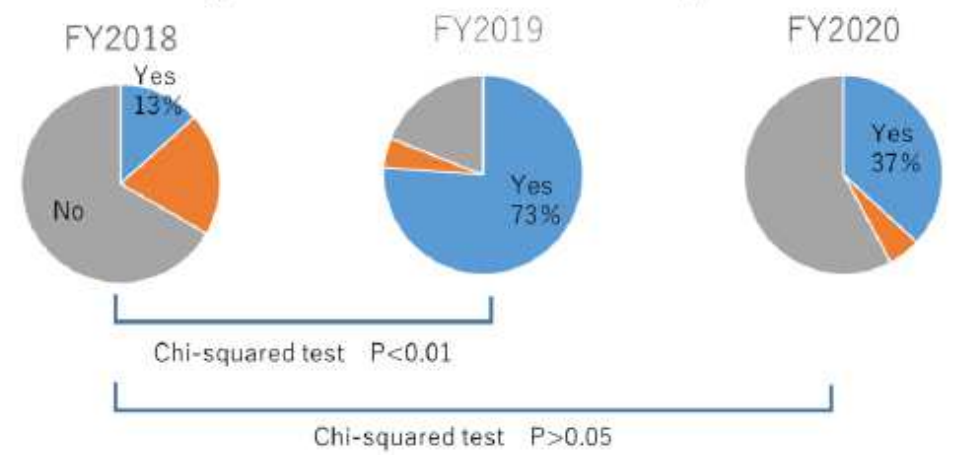

\section{Figure 1}

Results 1: Experiences and awareness of OSCE and SP 
I have learned about conditions in testing (OSCE).

FY2018

FY2019

FY2020

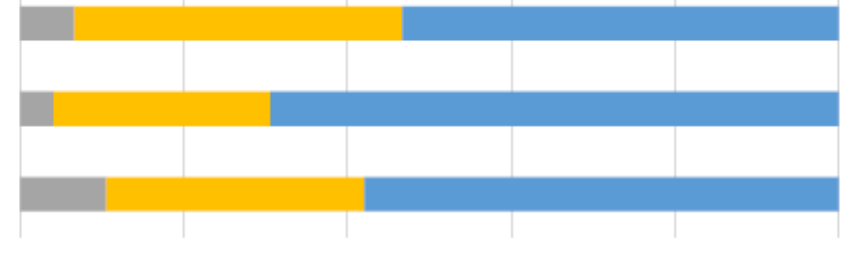

It was difficult to remember the scenario.

$20 \%$

$60 \%$

$80 \% \quad 100 \%$

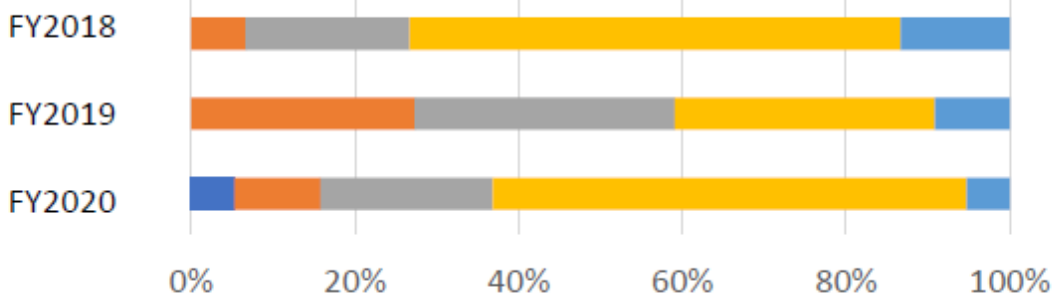

It was fun.

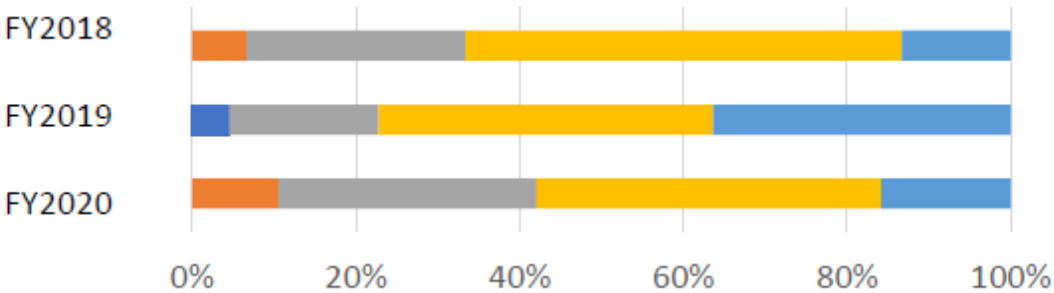

I felt involved in the frontline of education.

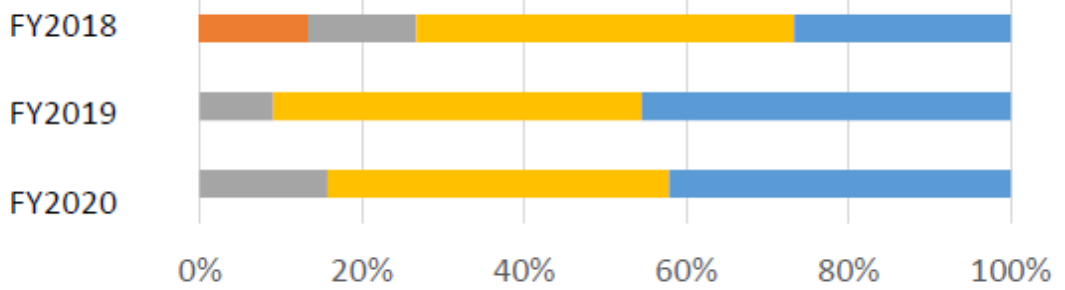

I felt the importance of communication.

FY2018

FY2019

Strongly agree

Agree somewhat

FY2020

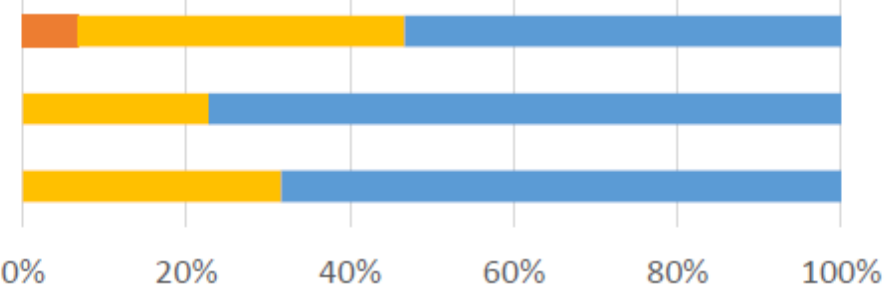

Neutral

Disagree somewhat

Completely disagree

Figure 2

Results 2: Thoughts about the SP experience 
If I have the opportunity, I want to do it again.

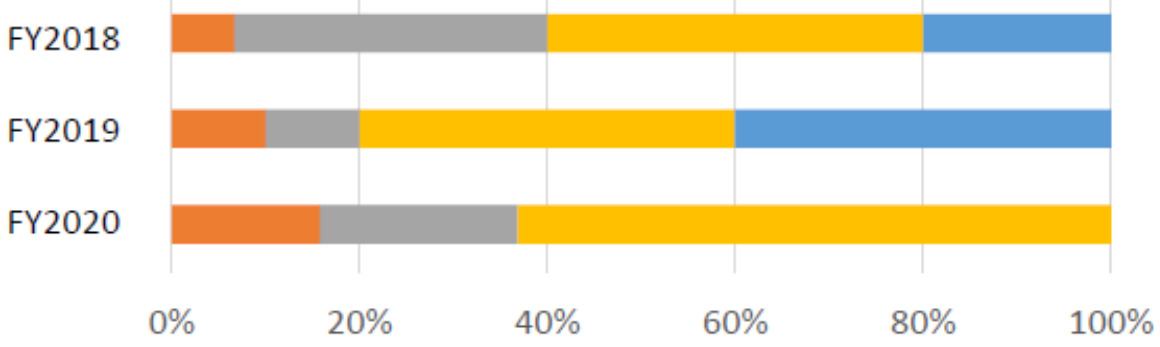

It has no relation to my current work.

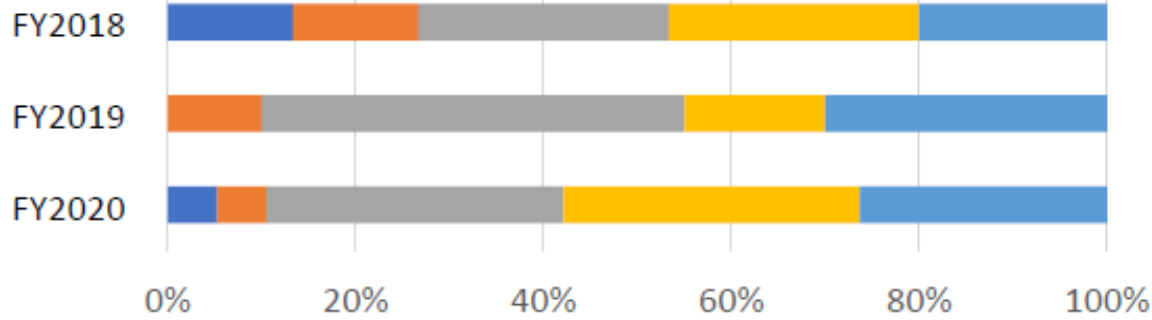

Other staff are busy and I have mixed feelings about encouraging them to try it.

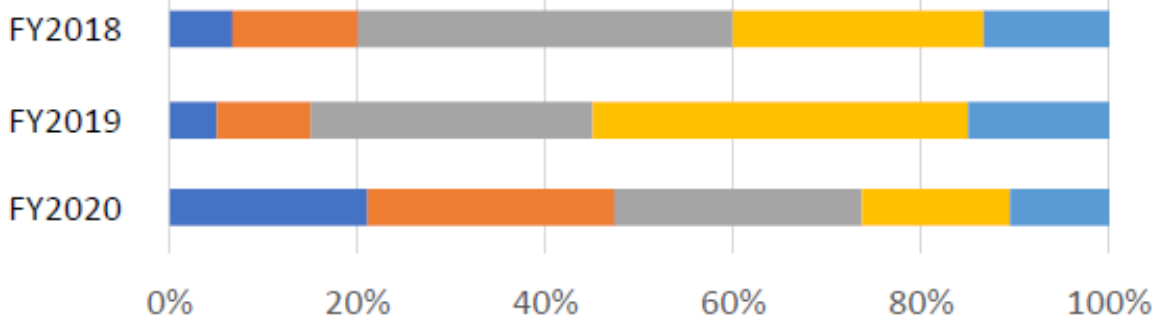

Staff of a medical school should do it.

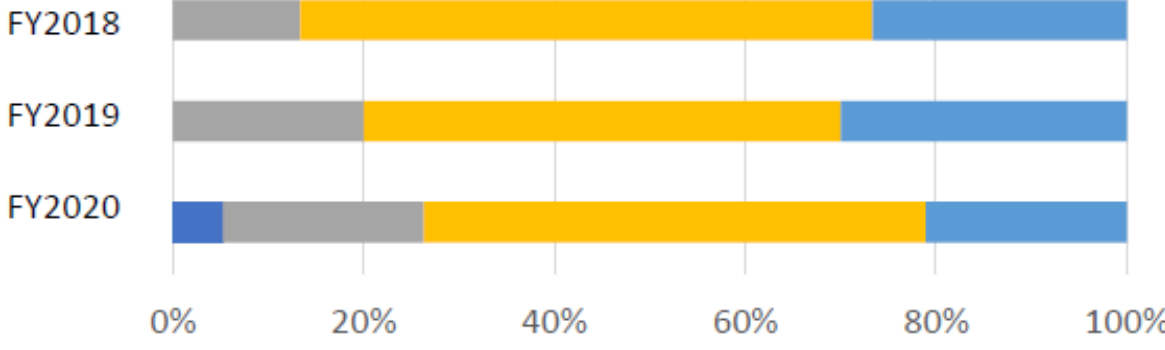

Strongly agree

Agree somewhat

Neutral

Disagree somewhat

Completely disagree

\section{Figure 3}

Results 3: Thoughts about staff acting as SPs in post clinical clerkship OSCE (1) 
Many staff should experience it.

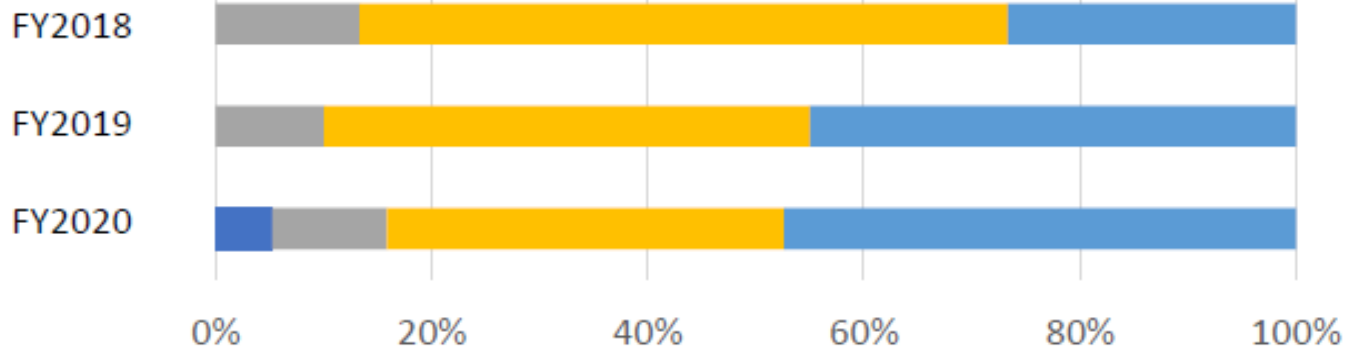

A simulated patient training association should be started.

FY2018

FY2019

FY2020

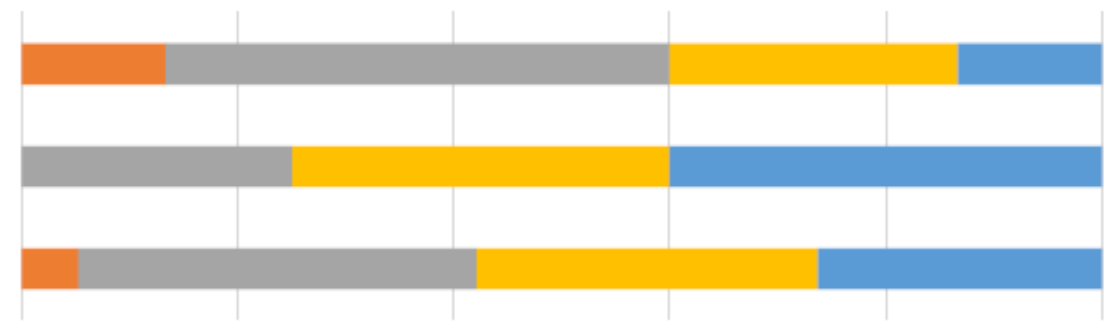

$0 \%$

$20 \%$

$40 \%$

$60 \%$

$80 \%$

$100 \%$

There should be a system for certifying staff who take simulated patient training.

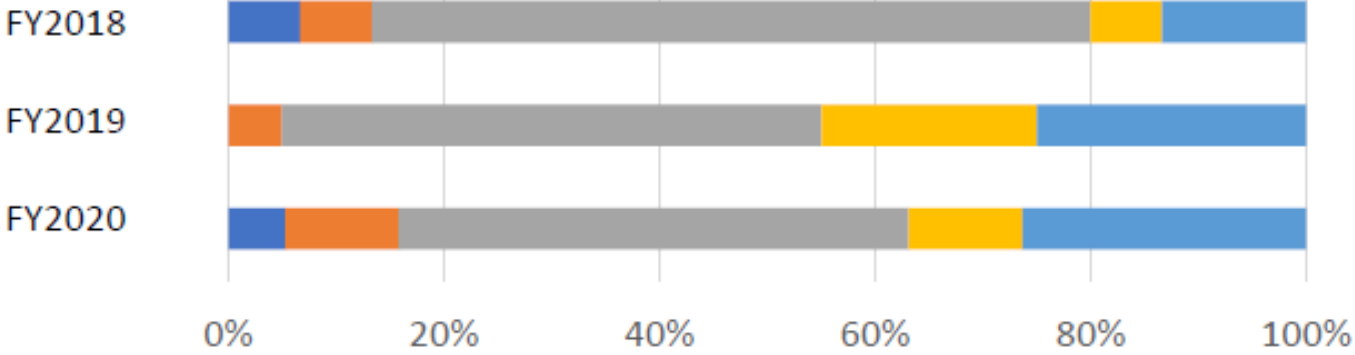

Strongly agree

Agree somewhat

Neutral

Disagree somewhat

Completely disagree

\section{Figure 4}

Results 4: Thoughts about staff acting as SPs in post-clinical clerkship OSCE (2) 